\title{
In vivo and in vitro study on the effect of Bacillus subtilis and its byproducts on Clostridium perfringens Type $A$
}

\author{
I. A. Radwan ${ }^{1 *}$, Eman R. Hassan ${ }^{2}$ \\ ${ }^{1}$ Department of Bacteriology, Mycology and Immunology Faculty of Veterinary Medicine, Beni-Suef \\ University, Beni-Suef 62511, Egypt. and ${ }^{2}$ Department of Poultry diseases, National Research \\ Center, Giza, Egypt.
}

\begin{abstract}
The objectives of this study were to screen the possible effects of $B$. subtilis and its soluble byproducts against $C$. perfringens, a causative agent of necrotic enteritis (NE) in chickens. The use of $B$. subtilis strain was found to be inactive in vitro against $C$. perfringens but its cell filtrate byproducts produced after growth of $B$. subtilis at $37^{\circ} \mathrm{C}$ with medium $\mathrm{pH}$ adjusted at 5.0, having inhibitory effect in the form of inhibitory zones; measured inhibition of $12 \mathrm{~mm}$. The produced anticlostridial factor was not affected by heat treatment at 70,100 or $121^{\circ} \mathrm{C}$ for 15 minutes. The study recorded the responses of broiler chickens to oral administration of $C$. perfringens and the possible antagonistic effects of $B$. subtilis and its cell-free filtrate byproducts in vivo. Results revealed that $B$. subtilis decreased the severity of intestinal necrotic lesions produced after oral inoculation of $C$. perfringens and the suggested anticlostridial effect was more clear when the cellfree filtrate produced by growing $B$. subtilis at $37^{\circ} \mathrm{C}$ with $\mathrm{pH} 5.0$ was added to feed at a dose of 20 $\mathrm{ml} / \mathrm{kg}$ of ration.
\end{abstract}

Substantial progress has been made in the development of probiotics, prebiotics and synbiotics, which are effective in increasing and maintaining the population of lactic acid bacteria in the intestine (Klein et al., 1998).

Bacillus subtilis is considered generally recognized as safe and has found application in the feed industry (Salminen et al., 1996). Necrotic enteritis, an enterotoxemic disease caused by Clostridium perfringens, leads to the development of necrotic lesions in the gut wall, resulting in mortality of poultry (Paulus and Rockepusch, 1996).

This disease is also multifactorial with complex and partially unknown epidemiology and pathogenesis (Kaldhusdal, 2000). Studies have shown increase in the concentration of $C$. perfringens cells in the gastrointestinal tract has been correlated with necrotic enteritis (Craven et al., 1999).

The objectives of this study were to screen the effect of Bacillus subtilis as a probiotic against $C$. perfringens Type $\mathrm{A}$, the causative agent of necrotic enteritis in poultry as well as the possible effect of $B$. subtilis byproduct as anticlostridial factor.

\footnotetext{
* Corresponding author. Tel.: +20 0822322066; fax: +20 822327982.

E-mail address: rahil@bsu.edu.eg

(Ismael A. Radwan)
}

\section{Materials and Methods \\ Bacterial strains and culture conditions}

Bacillus subtilis strain. This strain is standardized strain deposit No. DSM17299. It was inoculated into tryptic soya broth (Oxoid) supplemented with yeast extract $(6 \mathrm{~g} /$ liter $)$ (TSBYE broth) for 24 hours at $37^{\circ} \mathrm{C}$ then streaked onto tryptic soya agar supplemented with yeast extract and incubated for 24 hours at $37^{\circ} \mathrm{C}$ to obtain pure fresh colonies (Teo and Tan, 2006).

Clostridium perfringens Type A strain. This strain was previously isolated from typical cases of necrotic enteritis in broilers and completely identified biochemically according to Koneman et al., (1992). This strain was also characterized by molecular techniques according to Yoo et al., (1997).

\section{In vitro studies}

Antagonistic assays. The strain of Bacillus subtilis was grown in TSBYE broth and incubated at $37^{\circ} \mathrm{C}$. Isolated colony of $C$. perfringens grown onto sheep blood agar was inoculated into $10 \mathrm{ml}$ of thioglycolate broth (FTB) (Oxoid) at $37^{\circ} \mathrm{C}$ under anaerobic conditions using anaerogen pak (Oxoid). An overnight culture of $C$. perfringens was streaked (perpendicularly) onto the surface of TSAYE agar using a sterile cotton swap according to Teo and Tan (2006). The overnight culture of $B$. subtilis was streaked across the same agar plate 
bisecting the streak line of $C$. perfringens and the plate was incubated at $37^{\circ} \mathrm{C}$ under $5 \% \mathrm{CO}_{2}$ for 24 hours. Antagonistic effect of the test organism on $C$. perfringens was determined by the appearance of clear zone surrounding the junctions of the streak lines (Teo and Tan, 2006). Well diffusion assays. It was used according to Teo and Tan (2006). Molten TSAYE medium containing $0.7 \%$ agar at $45^{\circ} \mathrm{C}$ was inoculated with an $18 \mathrm{~h}$ culture of $C$. perfringens to obtain a final concentration of approximately $10^{4}$ to $10^{5}$ organisms per $\mathrm{ml}$. Ten milliliters of the seeded agar was then dispensed aseptically into sterile petri dishes containing $20 \mathrm{ml}$ of solidified TSAYE medium. Upon solidification of both agar layers, the surface of the agar was perforated using a sterilized cork borer to create wells of $8 \mathrm{~mm}$ in diameter. The wells were filled with $200 \mu 1$ per well of the test samples and the plates were incubated at $37^{\circ} \mathrm{C}$ for $18 \mathrm{~h}$ under anaerobic conditions. The diameters of the zones of inhibition were measured. Each well diffusion assay used for testing an antimicrobial factor with various parameters was conducted 3 times in duplicate.

Effect of growth temperature and $p H$ on the production of anticlostridial factor by B. subtilis. $B$. subtilis was grown aerobically in TSBYE broth at 37,45 and $50^{\circ} \mathrm{C}$ for $18 \mathrm{~h}$ with automatic shaking every 2 hours then the cultures were filtered through 0.45 sterile filters to obtain cellfree filtrate. On the other hand, cells of $B$. subtilis were grown in TSBYE broth adjusted to $\mathrm{pH}$ 4.0, 5.0, 6.0 and 7.0 and incubated aerobically at $37^{\circ} \mathrm{C}$ for $18 \mathrm{~h}$ with shaking every 2 hours. All cells of $B$. subtilis were removed by filteration through 0.45 sterile filters. The negative controls were sterile TSBYE broth adjusted to $\mathrm{pH} 4.0,5.0,6.0$, or 7.0. All inoculated plates were incubated anaerobically at $37^{\circ} \mathrm{C}$ for $18 \mathrm{~h}$.

Sensitivity of $B$. subtilis byproducts to temperature. Fifty milliliter of each of the cellfree filtrates of B. subtilis grown at $37^{\circ} \mathrm{C}$ and $\mathrm{pH}$ 4.0, 5.0, 6.0 and 7.0 were heated at 70, 100 and $121^{\circ} \mathrm{C}$ for 15 minutes. Each heat treated filtrate was dispensed into wells containing TSAYE medium and screened for anticlostridial activity. The inhibitory zones around the wells were determined after anaerobic incubation at $37^{\circ} \mathrm{C}$ for $18 \mathrm{~h}$.

In vivo study

Experimental infection with $C$. perfringens. Commercial broilers (Ross) were used. A total of 80 birds were divided into four equal groups:
The first group. Birds in this group were orally inoculated daily for 7 days, with $1 \mathrm{ml}$ $\left(2.0 \times 10^{8} \mathrm{CFU} / \mathrm{ml}\right)$ of an overnight culture of $C$. perfringens between 14 and 21 days of age (Olkowski et al., 2006).

The second group. Birds in this group were fed for 2 weeks (between 14 and 28 days of age) commercial ration contained cells of $B$. subtilis added at an inclusion rate of $10^{9} \mathrm{CFU} / \mathrm{kg}$ of feed (Teo and Tan, 2006).

The third group. Birds in this group were fed (between 14 and 28 days of age) commercial ration contained $B$. subtilis cell-free filtrate obtained after growth of $B$. subtilis in TSBYE broth at $37^{\circ} \mathrm{C}$ at $\mathrm{pH}$ 5.0. To each kilogram of ration, $20 \mathrm{ml}$ of the cell-free filtrate were added and mixed well immediately before use.

The second and third groups of chickens were additionally orally inoculated daily, with $1 \mathrm{ml}$ of $2.0 \times 10^{8} \mathrm{CFU} / \mathrm{ml}$ of an overnight culture of $C$. perfringens between 14 and 21 days of age.

The fourth group. acts as control non infected group.

No antibiotic growth promoter was supplemented in the diet of the negative control group except for maduramicin-ammonium (Alpharma). Enough lighting was provided during the night to assure continuous feeding and water intake. On day 29, all birds were euthanized and subjected to gross postmortem evaluation according to (Calnek et al., 1997).

\section{Results}

Anticlostridial effect of $B$. subtilis in vitro. After $24 \mathrm{~h}$ of incubation, the antagonistic effect of $B$. subtilis on the growth of $C$. perfringens could not be observed.

Effect of growth temperature and $\mathrm{pH}$ on the production of anticlostridial factor. By growing of $B$. subtilis at various growth temperatures, no zone of inhibition was observed with cell-free filtrates extracted from cultures grown at 45 and $50^{\circ} \mathrm{C}$. On the other hand, there was no zone of inhibition with $B$. subtilis filtrate grown in TSBYE broth at $\mathrm{pH}$ 4.0. However with growth at $\mathrm{pH} 5.0,6.0$ and 7.0, various degrees of anticlostridial activities were observed (Table 1). The maximum anticlostridial activity was observed at $\mathrm{pH}$ 5.0. No zone of inhibition was detected with negative controls using sterile TSBYE broth at $\mathrm{pH} 4.0,5.0,6.0$ and 7.0.

Effect of temperature on anticlostridial activity. Very small or no significant decreases in anticlostridial activities of the filtrates were observed when they were heated at 70,100 and 
$121^{\circ} \mathrm{C}$ for 15 minutes (Table 1 ).

\section{Experimental infection}

First group. Chicken of this group showed no mortalities. Gross lesions were apparent in the duodenum, jejunum, ileum and ceca in $60.0 \%$ of chickens. The intestinal wall appeared thin and friable. Intestinal mucosa was lined by yellow or greenish pseudomemberanes I 14 out of the 20 inoculated chickens. In areas with more advanced necrotic lesions, the intestinal mucosa was covered with a brownish, diphtheritic pseudomemberanes. The main clinical signs were decreased appetite, reluctance to move, diarrhea and ruffled feathers.

Second group. Intestinal necrosis was less advanced, the mesenteric vessels were engorged with blood, and the mucosa was lined by yellow membranes. No mortalities were recorded.

Third group. There were no clear changes could be seen in intestinal mucosa observed except mild, mostly focal gross changes in duodenum in the form of gray thickened mucosa.

Forth group. Mild, mostly focal changes in duodenum of control birds were recorded.

Table (1): The anticlostridial activities of $B$. subtilis byproducts under different cultural and incubation factors.

\begin{tabular}{lll}
\hline Treatment & & $\begin{array}{c}\text { Mean zones } \\
\text { of inhibition }\end{array}$ \\
\hline \multirow{3}{*}{ Growth temperature } & $37^{\circ} \mathrm{C}$ & $8 \mathrm{~mm}$ \\
& $45^{\circ} \mathrm{C}$ & $0.0 \mathrm{~mm}$ \\
& $50^{\circ} \mathrm{C}$ & $0.0 \mathrm{~mm}$ \\
& & \\
pH of growth medium & 5.0 & $0 \mathrm{~mm}$ \\
& 5.0 & $12 \mathrm{~mm}$ \\
& 6.0 & $10 \mathrm{~mm}$ \\
Heat & 7.0 & $8 \mathrm{~mm}$ \\
& $70^{\circ} \mathrm{C}$ & $8 \mathrm{~mm}$ \\
& $100^{\circ} \mathrm{C}$ & $7 \mathrm{~mm}$ \\
& $121^{\circ} \mathrm{C}$ & $7 \mathrm{~mm}$ \\
\hline
\end{tabular}

\section{Discussion}

This study was based on previous studies which demonstrated that probiotic microorganisms adhere to and colonize the epithelial cells of the gastrointestinal tract and their beneficial effects include competitive exclusion of pathogenic strains of $E$. coli (Watkins et al., 1982), Campylobacter jejuni (Morishita et al., 1997) and Salmonella Entertidis (Pascual et al., 1999); enhancing the growth and viability of beneficial gut microflora (Hosoi et al., 2000) and improved digestion and absorption of nutrients (Thomke and Elwinger, 1998) in chickens. Other criteria used include production of antimicrobial factors (Salminen et al., 1996). A number of lactic acid bacteria have been shown to exhibit various degrees of antimicrobial activities against clostridium species (West and Warner, 1988; Alander et al., 1999).

In the present study, strain of $B$. subtilis (deposit No. DSM17299) was tested for antagonism toward local isolate of $C$. perfringens Type A isolated from typical cases of necrotic enteritis in broiler chickens.

The in vitro antagonistic effect of $B$. subtilis on the growth of $C$. perfringens could not be observed meanwhile findings obtained showed that filtrates of the bacillus strain contained antimicrobial factor against $C$. perfringens when it grown at $\mathrm{pH} 5.0,6.0$ and 7.0 at incubation temperature of $37^{\circ} \mathrm{C}$ and the maximum anticlostridial activity was observed at $\mathrm{pH}$ 5.0. Production of bacteriocins by Bacillus species has been reported by (Von Tersch and Carlton, 1983; Jansen and Hirsehmann,1944; Pattnaik et al., 2001). Results of Teo and Tan (2006) revealed the anticlostridial bacteriocin of $B$. subtilis.

The inhibitory activity of the anticlostridial factor was maintained after heating at 70,100 or $121^{\circ} \mathrm{C}$ for 15 minutes (Table 1). Similar findings were described by (Baquero and Moreno, 1984; Teo and Tan, 2006). The maximum antimicrobial activity was observed when cells of $B$. subtilis were grown in broth at $\mathrm{pH} 5.0$ and incubated at $37^{\circ} \mathrm{C}$ to disagree with the results of Teo and Tan (2006) which indicated that the maximum activities were observed at $\mathrm{pH}$ 6.2.3

After experimental infection, the in vivo study clarified that no mortalities were recorded. The first group which inoculated orally with $C$. perfringens showed postmortem lesions in the form of thin friable intestinal wall, the mucosa was lined by greenish pseudomembranes or brownish diphtheritic pseudomembranes meanwhile, group which received $C$. perfringens orally and B. subtilis in feed recorded less advanced intestinal necrosis with yellow membranes covering the intestinal mucosa. The birds which received cell-free filtrate ob $B$. subtilis grown at $37^{\circ} \mathrm{C}$ with $\mathrm{pH} 5.0$, recorded no obvious intestinal changes except mild focal changes in duodenum. The obtained results indicate the role of $B$. subtilis byproducts in exhibiting antimicrobial activities against $C$. perfringens as reported by (Salmenin et al., 
1996). Because of the undetected clinical signs, the lesions observed in this study can be classified as sub-clinical. The lesions observed in this study are remarkably similar to those described by (Kaldhusdal and Hofshagen,1992; Olkowski et al., 2006).

\section{References}

Alander, M.; Satokari, R.; Korpela, R.; Saxelin, M.; Vilpponen-Salmela, T.; Mattila-Sandholm, A. and von Wright, T. (1999): Persistence of colonization of human colonic mucosa by a probiotic strain, Lactobacillus rhamnosus GG, after oral consumption. Appl. Env. Microbiol., 65:351-354.

Baquero, F. and Moreno, F. (1984): The microcins. FEMS Microbiol. Lett. 23:117-124.

Calneck, B. W.; Barnes, H. J.; Beard, C. W.; McDougald, L. R. and Saif, Y. M. (1997): Diseases of poultry. $10^{\text {th }}$ ed. Ames, Iowa, USA.

Hosoi, T.; Ametani, A.; Kiuchi, K. and Kaminogawa, S. (2000): Improved growth and viability of lactobacilli in the presence of Bacillus subtilis (natto) or subtilin. Can. J. Microbiol., 46:892-897.

Jansen, E. F. and Hirschmann, D. J. (1944): Subtilin, an antibacterial factor of Bacillus subtilis: culturing condition and properties. Arch. Biochem., 4:297-309.

Kaldhusdal, M. I. (2000): Necrotic enteritis as affected by dietary ingredients. World Poult., 16:42-43.

Kaldhusdal, M., Hofshagen, M., (1992): Barley inclusion and avoparcin supplementation in broiler diets. 2. Clinical, pathological, and bacteriological findings in a mild form of necrotic enteritis. Poult. Sci., 71:1145-1153.

Klein, G.; Pack, A.; Bonaparte, C. and Reuter, G. (1998): Taxonomy and physiology of probiotic lactic acid bacteria. Int. J. Food Microbiol., 41:103- 125.

Konemann, E. W; Allen, S. D.; Dowell, V. R. and Sommers, H. M. (1992): Colour atlas of Diagnostic Microbiology. $2^{\text {nd }}$ ed., J. B. Lippicott Co., London.

Morishita, T. Y.; Aye, P. P.; Harr, B. S.; Cobb, C. W. and Clifford, J. R. (1997): Evaluation of an avian-specific probiotic to reduce the colonization and shedding of
Campylobacter jejuni in broilers. Avian Dis., 41:850-855. Olkowski, A. A.; Wojnarowicz, C.; Chirino-Trejo, M. and Drew, M. D. (2006): Responses of broiler chickens orally challenged with Clostridium perfringens isolated from field cases of necrotic enteritis. Res. Vet. Sci., 81:99108.

Pascual, M.; Hugas, M.; Badiola, J. I. ; Monfort, J. M. and Garriga, M. (1999): Lactobacillus salivarius CTC2197 prevents Salmonella enteritidis colonization in chickens. Appl. Env. Microbiol., 65:4981-4986.

Pattnaik, P.; Kaushik, J. K.; Grover, S. and Batish, V. K. (2001): Purification and characterization of a bacteriocin-like compound (lichenin) produced anaerobically by Bacillus licheniformis isolated from water buffalo. J. Appl. Microbiol., 91:636-645.

Paulus, C. and Ruckebusch, J. P. (1996): Necrotic enteritis (NE). Zootec. Int., 19:40-42.

Salminen, S.; Isolauri, E. and Salminen, E. (1996): Clinical uses of probiotics for stabilizing the gut mucosal barrier: successful strains and future challenges. Antonie Leeuwenhoek, 70:347-358.

Teo, A. Y. L and Tan H. M. (2006): Inhibition of Clostridium perfringens by a Novel Strain of Bacillus subtilis Isolated from the Gastrointestinal Tracts of Healthy Chickens. Appl. Env. Microbiol., 71(8): 4185-4190.

Thomke, A. and Elwinger, K. (1998): Growth promotants in feeding pigs and poultry. III. Alternatives to antibiotic growth promotants. Ann. Zootech. (Paris) 47:245-271.

Von Tersch, M. A. and Carlton, B. C. (1983: Bacteriocin from Bacillus megaterium ATCC 19213: comparative studies with megacin A216. J. Bacteriol., 155:866-871.

Watkins, B. A.; Miller, B. F. and Neil, D. H. (1982): In vivo effects of Lactobacillus acidophilus against pathogenic Escherichia coli in gnotobiotic chicks. Poult. Sci., 61:12981308.

West, C. A. and Warner, P. J. (1988): Plantacin, B, a bacteriocin produced by Lactobacillus plantarum NCDO 1193. FEMS Microbiol. Lett., 49:163.

Yoo, H. S.; Lee, S. U.; Park, K. Y. and Park, Y. H. (1997): Molecular typing and epidemiological survey of prevalence of Clostridium perfringens types by multiplex PCR. J. Clin. Microbiol., 35 (1): 228-23.

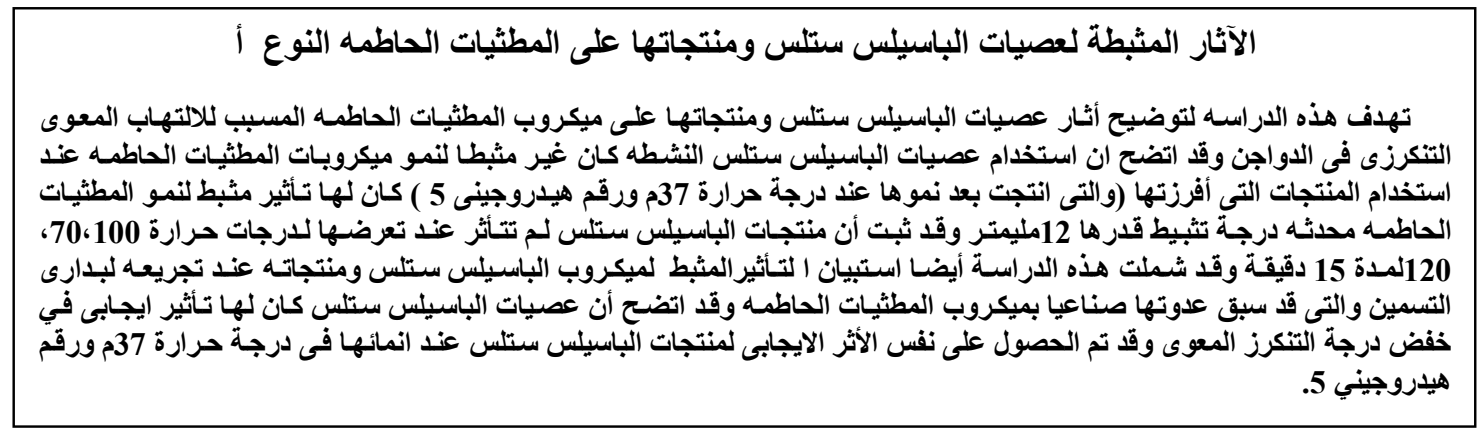

